\title{
Suffocation, choking, and strangulation in childhood in England and Wales: epidemiology and prevention
}

\author{
James W Nixon, Alison M Kemp, Sara Levene, J R Sibert
}

Department of Child Health, University of Wales College of Medicine, Llandough Special Children Centre, Penarth, South Glamorgan CF64 2XX

J W Nixon

A M Kemp

J R Sibert

Child Accident

London

$S$ Levene

Correspondence to: Professor Sibert.

Accepted 16 September 1994 Prevention Trust,

\begin{abstract}
The causes, classification, and prevention of mechanical asphyxial death in children were examined. The Office of Population Censuses and Surveys (OPCS) identified children, under 15 years of age, who had died as a result of choking, suffocation, or strangulation in England and Wales during the years 1990 and 1991. Cases in the International Classification of Diseases (ICD) codes of E911-3, E953, E963, and E983 were selected and case details from HM coroners' records and the death certificates were extracted.
\end{abstract}

The OPCS identified 136 children (99 boys, 37 girls) in the two year period, $65 \%$ were under 3 years of age. The children were classified as dying from choking ( 21 cases), aspirating gastric contents (39 cases), suffocation ( 29 cases), strangulation (11 cases), and hanging (36 cases). The strangulation cases could be further subdivided into a group of 12 younger children who were suspended from ligatures around the home and a group of 21 boys (8-14 years) who died of self initiated hanging. Overall, 11 children were deliberately killed and 31 children died in beds or cots. Children whose deaths are classified as being due to aspiration of

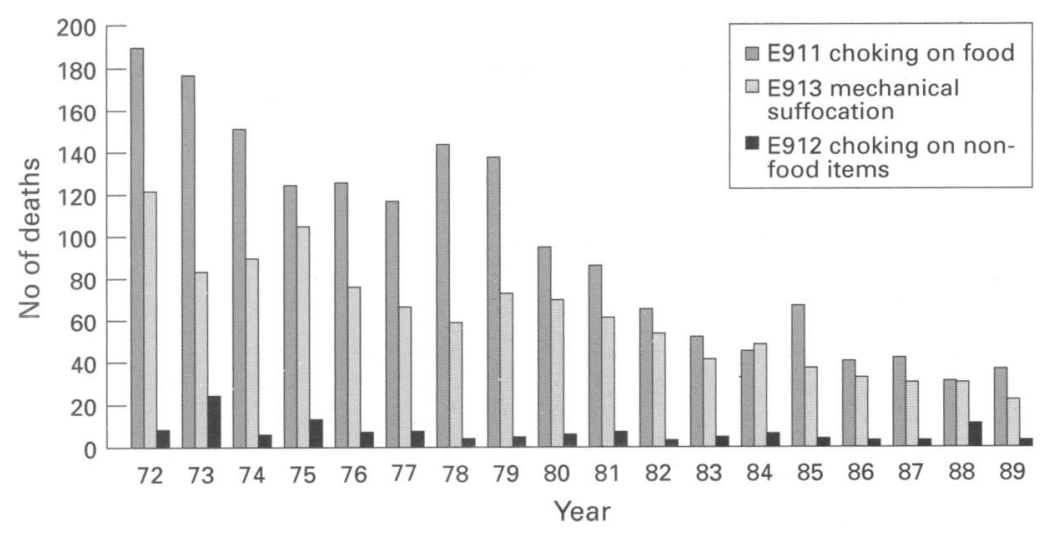

Choking and mechanical suffocation 1972-89 (OPCS mortality statistics series DH4). vomit appear to be cases of the sudden infant death syndrome or background medical conditions.

This study suggests the need for advice on maintaining a safe sleeping environment. Only one child choked on a toy and European Standards for Toy Safety appear to have been successful. The prevention of hanging in the group of older boys needs further exploration.

(Arch Dis Child 1995; 72: 6-10)

Keywords: choking, suffocation, strangulation.

The Office of Population Censuses and Surveys (OPCS) lists asphyxia (International Classification of Diseases (ICD) 911-913), excluding drowning, as the third most common cause of accidental death in children under 15 years of age in England and Wales, ${ }^{1}$ after road traffic accidents and thermal injury. Asphyxia is also a leading cause of accident related death in children under 1 year of age. ${ }^{12}$ We have analysed mortality statistics for children from the OPCS over the last 20 years and found there has been a steady fall in the number of childhood deaths registered as choking or mechanical suffocation (figure). This may be due to improved medical treatment of foreign body aspiration cases through bronchoscopy, improved infant feeding practices, modification of baby equipment, and 'small part' regulations through consumer safety standards. However, in the absence of a comprehensive British study of the subject, we do not have an adequate explanation.

Previous reports have identified food, plastic bags, ${ }^{2}$ dummies, ${ }^{3}$ water beds and soft bedding, ${ }^{4}$ and toy balloons ${ }^{25}$ as agents of choking and suffocation. There are reports of strangulation by cords, furniture, clothes, and collapsible washing lines. ${ }^{6}$ Hanging, whether accidental or suicidal ${ }^{7}$ is a rare cause of death, primarily in boys. ${ }^{8}$ Asphyxial injury in children may be due to abuse both in the context of deliberate suffocation or strangulation. In this study we have analysed deaths to children from mechanical asphyxia to determine the 
Table 1 Deaths from choking, strangulation, and suffocation

\begin{tabular}{|c|c|c|c|c|}
\hline Classification & $\begin{array}{l}\text { Total } \\
\text { No }\end{array}$ & Boys & Girls & $\begin{array}{l}\text { Mean } \\
\text { age } \\
\text { (years) }\end{array}$ \\
\hline $\begin{array}{l}\text { Choking } \\
\text { Foreign body } \\
\text { Food }\end{array}$ & $\begin{array}{l}21 \\
10 \\
11\end{array}$ & $\begin{array}{r}14 \\
5 \\
9\end{array}$ & $\begin{array}{l}7 \\
5 \\
2\end{array}$ & $\begin{array}{l}2 \cdot 3 \\
1 \cdot 2 \\
3 \cdot 3\end{array}$ \\
\hline $\begin{array}{l}\text { Inhalation of vomit } \\
\text { Associated with medical conditions } \\
\text { Cerebral palsy } \\
\text { Bronchopneumonia or bronchiolitis } \\
\text { During a fit } \\
\text { Extreme prematurity } \\
\text { No predisposing cause (probable SIDS) } \\
\text { Homicide } \\
\text { Unknown }\end{array}$ & $\begin{array}{r}39 \\
19 \\
5 \\
6 \\
8 \\
1 \\
15 \\
2 \\
3\end{array}$ & $\begin{array}{r}25 \\
14 \\
4 \\
5 \\
5 \\
1 \\
8 \\
2 \\
1\end{array}$ & $\begin{array}{r}14 \\
5 \\
1 \\
1 \\
3 \\
0 \\
7 \\
0 \\
2\end{array}$ & $\begin{array}{l}2 \cdot 3 \\
2 \cdot 9 \\
4 \cdot 8 \\
0 \cdot 9 \\
3 \cdot 6 \\
0 \cdot 2 \\
0 \cdot 5 \\
1 \cdot 7 \\
7 \cdot 9\end{array}$ \\
\hline $\begin{array}{l}\text { Suffocation } \\
\text { Suffocated in adult beds } \\
\text { Overlain } \\
\text { Slipped gap between wall and bed } \\
\text { Plastic bags } \\
\text { Suffocated in cot } \\
\text { Chest freezer } \\
\text { Homicide } \\
\text { Crushed } \\
\text { Plastic bag } \\
\text { Unknown }\end{array}$ & $\begin{array}{r}29 \\
12 \\
6 \\
4 \\
2 \\
5 \\
3 \\
5 \\
2 \\
1 \\
1\end{array}$ & $\begin{array}{r}22 \\
6 \\
2 \\
2 \\
2 \\
4 \\
3 \\
5 \\
2 \\
1 \\
1\end{array}$ & $\begin{array}{l}7 \\
6 \\
4 \\
2 \\
0 \\
1 \\
0 \\
0 \\
0 \\
0 \\
0\end{array}$ & $\begin{array}{l}2 \cdot 2 \\
0.7 \\
0.5 \\
0.7 \\
0.9 \\
0.7 \\
4 \cdot 9 \\
4 \cdot 5 \\
6.5 \\
0.5 \\
2 \cdot 6\end{array}$ \\
\hline $\begin{array}{l}\text { Strangulation and hanging } \\
\text { Strangulation } \\
\text { Caught between mattress and cot } \\
\text { Homicide } \\
\text { Caught in frame of old pram } \\
\text { Caught in bed frame } \\
\text { Accidental hanging } \\
\text { Ligatures in cot (dummy cord, curtain cords) } \\
\text { Loose cords (phone cable blind pull, etc) } \\
\text { Necklace } \\
\text { Clothing on pram } \\
\text { Self initiated hanging }\end{array}$ & $\begin{array}{r}47 \\
11 \\
5 \\
4 \\
1 \\
1 \\
15 \\
6 \\
7 \\
1 \\
1 \\
21\end{array}$ & $\begin{array}{r}38 \\
6 \\
4 \\
0 \\
1 \\
11 \\
5 \\
6 \\
0 \\
0 \\
21\end{array}$ & $\begin{array}{r}4 \\
1 \\
1 \\
1 \\
1 \\
0\end{array}$ & $\begin{array}{r}4 \cdot 5 \\
1 \cdot 8 \\
1 \cdot 2 \\
2 \cdot 3 \\
2 \cdot 9 \\
0 \cdot 9 \\
2 \\
1 \\
2 \cdot 3 \\
7 \cdot 8 \\
0 \cdot 8 \\
12 \cdot 3\end{array}$ \\
\hline
\end{tabular}

^Including one child with cerebral palsy.

extent and nature of the problem, to investigate the appropriateness of the classification of deaths, and to ascertain the potential for prevention.

\section{Methods}

The OPCS identified for us children who had died as a result of choking, suffocation, or strangulation in England and Wales during the years 1990 and 1991 . We selected cases in the ICD codes of E911 (inhalation of food); E912 (inhalation of other object); E913 (accidental mechanical suffocation); E953, E963, and E983 non-accidental strangulation and hanging. We did not include cases of asphyxiation from carbon monoxide or other toxic gases in the study. We obtained additional information from the inquest files of HM coroners. We included children in the study if they were less than 15 years of age. We categorised the cases according to the mechanism of asphyxiation. We used the following categories and definitions:

- Choking: internal obstruction of an airway by a foreign body or food.

- Aspiration of vomit: internal obstruction of airways secondary to inhalation of gastric contents.

- Suffocation: obstruction of the airway by covering the nose and mouth or through starvation of oxygen through enclosure.

- Strangulation: the airway was obstructed by external pressure other than to the nose or mouth.

- Hanging: a form of strangulation by suspension from a ligature.

\section{Results}

We identified 136 children less than 15 years of age who died from mechanical asphyxia in England and Wales during the two year period 1990 and 1991 . We received death registration forms for" all these cases and detailed HM coroners' reports for $85 \%$. We show the details of the children in table 1 .

There were 99 boys and 37 girls. The modal age for girls was in the first year of life while for boys there were two modal peaks: at less than 1 year of age and in the early teenage years. The annual mean incidence was 0.7 per 100000 children under 15 years old' and 3.8 per 100000 children at risk under 1 year of age. Thirty one deaths occurred in a bed or a cot. Eleven children were deliberately killed. These included two children who aspirated vomit in association with severe non-accidental injuries, five children who were suffocated, and four children who were strangled.

\section{CHOKING}

Twenty one children died from choking. Ten toddlers choked on a foreign body that they had picked up and put in their mouths. The foreign bodies aspirated included a marble, conker, silver and tissue paper, a small toy, a dummy, and a stone. Eleven older children choked on food while eating. Two of the children who choked on food had Down's syndrome. The most common foods were fruit and the stones and pips from fruit (five cases). One child choked on a pea, two on bread, one on a piece of sausage, and the remaining two on unspecified food items.

\section{ASPIRATION OF VOMIT}

Thirty nine children had a cause of death recorded as asphyxia secondary to inhalation of vomit. We did not consider that the deaths of most of these children were correctly classified as an accident. In 19 cases there was a preexisting medical condition such as cerebral palsy, epilepsy (eight children aspirated vomit during a fit), or bronchopneumonia. In 15 cases we found no predisposing cause of the aspiration of vomit, which was a postmortem finding. These children were infants all under 14 months and 13 of them were younger than 7 months of age. Two babies aspirated after a feed but in 13 cases the aspiration occurred during sleep. Two children in this group had a cause of death recorded as inhalation of vomit in association with sudden infant death syndrome (SIDS). We obtained details of the sleeping position in five cases and that was prone.

\section{SUFFOCATION}

Twenty nine children suffocated. Twelve children under 1 year of age accidentally suffocated in adult beds. Six babies were recorded as overlain, one by a mother in diabetic coma, one by a mother incapacitated by alcohol, one by a mother who was grossly obese, two were babies less than 2 months of age, and one was 
the youngest of seven children who were in bed together when it collapsed. Five children between 7 and 11 months old suffocated in their cot. Three children suffocated in one incident in a chest freezer. They had been playing and shut themselves in the freezer and were unable to escape. Five children were unlawfully killed. All the perpetrators were close family members: the father in three instances (two of whom themselves committed suicide), a mother and uncle in the other cases.

\section{STRANGULATION AND HANGING}

Forty seven children died from constriction around the neck: 11 were cases of strangulation and 36 of hanging. These included seven children who were strangled in association with a product: five of these children had their heads caught between the mattress and a defective cot side or wall. Two had similar accidents involving a pram and wrought iron bed head. Four girls were deliberately strangled by a parent.

The age distribution of the hanging cases demonstrated two distinct age groups. The younger group ( $0-7$ years) included 15 victims of accidental hanging who were killed by cords, necklaces, or clothing around the house. The group of older boys over 8 years of age were cases of self initiated hanging. In the majority of cases the boys were involved in play that had gone badly wrong. In three cases there had been an emotional disturbance before the event that was possible suicide and in one case there was evidence of autoerotic activity.

\section{Discussion}

Mechanical asphyxial deaths in children are a significant problem in England and Wales. These cases of choking, suffocation, and strangulation are predominantly accidental in origin: however, they do include a number of incidents of homicide ${ }^{910}$ (that reflect the spectrum of child killing and fatal child abuse) and cases where inhalation of vomit is the reported cause of death. When we excluded the children who had been deliberately killed and those with inhalation of vomit, we classified only $88(65 \%)$ of the cases as true accidents. We therefore advise caution when interpreting accident statistics quoted directly from ICD codes. ${ }^{1}$

The cases classified as being due to aspiration of vomit include some children with pre-existing medical conditions: such as cases of cerebral palsy, epilepsy, and chest infection. They also include a group of babies with unexplained inhalation of vomit found at postmortem examination: their age range coincides with that of SIDS and the majority of cases died in their sleep. Knight believes that, without clinical corroboration of aspiration of gastric contents, the finding of such aspiration by necropsy only is to be regarded with reservation. ${ }^{11} \mathrm{He}$ reports the presence of gastric contents in $25 \%$ of cases of SIDS: most likely resulting from agonal aspiration secondary to the terminal event. We believe that the majority of the cases of babies in our study who were classified as being due to inhalation of vomit, without other cause, should be correctly classified as the SIDS.

Mechanical asphyxiation is distinctly a problem in the baby and toddler age group with $65 \%$ of the children under 3 years of age. Boys, who hang themselves, cause a second peak in early teenage years. Other studies show a similar age pattern. ${ }^{12} 13$ The sex ratio with male preponderance is a typical finding in most childhood accident statistics. ${ }^{1}$

There is a strong relationship between the level of the child's development and the accident mechanism. Child victims of choking on foreign bodies are in the oral phase of development: they naturally put small objects straight to the mouth. We found no child younger than 6 months when the ability to manipulate a small object successfully into the mouth is not present. Young babies who asphyxiated in bed did so when they fell into a gap between bed and wall or between a faulty cot side. They neither had the strength nor motor agility to recover themselves. Older toddlers, however, succumbed while standing in the cot and their head became entangled in ligature near the cot or when clothing or dummy cords became caught on the cot side. This age group also has the manual dexterity to pull a plastic bag into the cot. We can extend this developmental theme to include the older boys who, in play or anger, imitated behaviour portrayed in the media and hung themselves with drastic consequences. This age and development specificity of the children who died indicate that prevention programmes should be directed at those involved with children under 5 years, in particular through the child surveillance programme. We should aim education programmes at raising awareness, so that parents can make their child's environment as safe as possible.

Effective measures aimed at the prevention of choking should also reduce the cases of inhalation of foreign body admitted to hospital for bronchoscopy. Davies et al estimate these cases amount to one in 14000 children served by a district general hospital in England. ${ }^{14}$ They carry a considerable morbidity and an estimated mortality rate of $7 \cdot 5 \% .{ }^{12}$ The cases we describe in this study are only a fraction of a very much larger problem. ${ }^{12-15}$ Parents need to know about the dangers of small objects, which must be kept out of the reach of toddlers, and the importance of supervising children while eating. This is particularly the case with children who have learning difficulties. Education programmes act as a back up to environmental safety requirements such as the European Standards for Toy Safety.

The lack of a significant pattern of choking incidents with non-food items (in particular coins, toys, and pen caps) encouraged us. The items inhaled were similar to those reported in other studies. ${ }^{21216}$ Coins are the most commonly aspirated or inhaled item seen in cases referred to hospital. ${ }^{1617}$ Toys caused 
Table 2 Advice on maintaining a safe sleeping environment

- A baby should never sleep in a faulty cot

- Dummy cords and necklaces in bed should be discouraged

- Cots should be positioned away from curtain cords, small items, and plastic bags

- Babies and toddlers should sleep in age appropriate cots

- Cot safety standards should be maintained and extended to retailed second hand equipment

only one choking death in our study. The toy involved had been purchased in 1980 and met the standard for small parts of toys at that time. Trading standards officers need to continue to enforce the European Standards for Toy Safety as they do appear to have been successful. In the past children have died from choking on pen caps. This resulted in work on venting (pen caps manufactured with a hole to allow passage of air) and this has been successful.

Beds and cots were implicated directly as the mechanism of injury in more than a third of accidental deaths. There are similar reports in the literature. ${ }^{4}$ Cot design is currently subject to British Standard BS1753 1989. No death could be directly attributed to cot design but the safety of equipment is highly dependent on its maintenance and correct usage. Cots are expected to have a long life span and are frequently used across generations. There is also a market for second hand equipment. There needs to be a mechanism to extend safety standards to retailed second hand items. We should encourage facilities to service and maintain baby equipment as part of safe community programmes. ${ }^{18} \mathrm{We}$ stress the importance of a child sleeping in an age appropriate cot or bed, of not using faulty cots and beds, positioning cots away from curtain cords and other potential ligatures and plastic bags. We should discourage children having 'dummy cords' in bed or excess clothing. HM coroners have commented on the practice of placing cords or ribbons around a young child's neck for any purpose. The danger of these cords near cots has been reported previously. ${ }^{1920}$ Safe sleeping practices could be stressed within the child surveillance programme by the primary care team, in parent held records, and by national publicity (see table 2 ).

There were cases where a child was overlain by an adult in bed. We have previously reported a case of drowning in a baby where the mother suffered an epileptic fit. ${ }^{21}$ These tragic cases are fortunately rare but suggest the value of specialist advice to maximise safety provisions into the child's environment where the mother may be prone to periods of diminished supervision. Historically, overlying was regularly listed as a cause of death in young babies $^{22}$; it is now a largely unrecognised entity and superseded by SIDS.

Feldman and Simms reported strangulations involving playground equipment. ${ }^{23}$ Improvements in playground equipment design over the past decade may have had an influence as only one case involving a bag and a slide occurred in this study.

Children who died from hanging came from two clear groups. Prevention of accidental hangings in the younger group relies on the vigilance of parents tying cords well out of the reach of toddlers and safe positioning of the cot in the bedroom. The older group of exclusively boys presents more challenges in the field of prevention. Education programmes may not have the desired effect on what is a recognised but infrequent event. Currently there is a vogue for blaming the media for exposing children to detrimental forms of behaviour, there could be a place for blaming the media in this case but there is no supportive evidence in our study. Cooke et al, however, describe a case of a child enacting a judicial hanging scene viewed on television. ${ }^{24}$ There is no suggestion that these cases have increased in the past 20 years $^{25}$ or are any more prevalent in other parts of the world. ${ }^{824}$ Clark and his colleagues describe similar cases in the USA with three cases of unequivocal suicide. We found three previously stable boys who indulged in an impulsive form of behaviour after an argument or household disharmony. Reports of children with strangulation associated with autoerotic behaviour are rare. ${ }^{26} \mathrm{We}$ found one case with supportive evidence of penile trauma.

Accidental mechanical asphyxia is a multifaceted subject but clearly mainly a problem in the preschool age group. It is difficult to see how further legislative changes can be made to ensure environmental safety in this field, although it is essential that strict safety standards for cots, prams, and small parts of toys are maintained within the European Community. Preventive education programmes and home checks need to be offered as part of health visitor component of the child surveillance programme. Tertinger et al have piloted a scheme specific to the reduction of household mechanical suffocation hazards in high risk families. ${ }^{27}$ This programme of household checks and education feedback was successful in producing sustained change but it was highly intensive and involved only six families. However, this provides a model and encouragement for the development of future educational preventive programmes.

We are very grateful to the Coroners Society and to all the HM coroners who responded to our study. We are grateful to the help we have had from the OPCS and to the Catherine Jenkins Trust for financial support.

Dr Nixon is a visiting senior research fellow from the Department of Child Health, University of Queensland, Brisbane, Australia.

1 Office of Population Censuses and Surveys. OPCS Monitor PP1 93/1. London: OPCS, 1993.

2 Baker SP, Fisher RS. Childhood asphyxiation by choking or suffocation. $\mathfrak{F A M A}$ 1980; 244: 1343-6.

3 Barrett TG, Debelle GD, Cranston AJ. Minerva. BMF 1993; 306: 76.

4 Gilbert-Barness E, Hegstrand L, Chandra S, et al. Hazards of mattresses, beds and bedding in deaths of infants. $A m \mathcal{F}$ Forensic Med Pathol 1991; 12: 27-32.

5 Ryan CA, Yacoub W, Paton T, Avard D. Childhood deaths from toy balloons. Am F Dis Child 1990; 144: 1221-4.

6 Roberton D, Rookwood K, Rutter N. Collapsible washing lines: a strangulation hazard. BMF 1981; 282: 1664.

7 Dudley M, Waters B, Kelk N, Howard J. Youth suicide in New South Wales: urban-rural trends. Med $\mathcal{F}$ Aust 1992; 156: 83-9.

8 Clark MA, Feczko JD, Hawley DA, Pless JE, Tate LR, Fardal $P$. Asphyxial deaths due to hanging in children. f Forensic Sci 1993; 38: 344-52. 
9 Meadow R. Suffocation, recurrent apnoea, and sudden infant death. F Pediatr 1990; 117: 351-7.

10 Pearn J, Wilkey I, Petrie G, Nixon JW. Neonaticide, infanticide and child homicide. Med Sci Law 1982; 22: 31-5.

11 Knight BH. The significance of the post mortem discovery of gastric contents in the air passages. Forensic Science 1975; 6: 229-34.

12 Menendez AA, Cruz FG, Seda FJ, Velez W, Pinedo JT Foreign body aspiration: experience at the university podiatric hospital. Puerto Rico Health Sciences fournal 1991; 10: 127-33.

13 Steen K, Zimmerman T. Tracheo-bronchial aspiration of foreign bodies in children: a study of 94 cases. Lanryngoscope 1990; 100: 525-9.

14 Davies H, Gordon I, Matthew DJ, et al. Long term follow up of inhalation of foreign body. Arch Dis Child 1990; 65: 619-21.

15 Al Hilou R. Inhalation of foreign bodies by children: review of experience with 74 cases from Dubai. $\mathcal{f}$ Laryngol Otol 1991; 105: 466-70.

16 Reilly JS, Walter MA. Consumer product aspiration and ingestion: analysis of emergency room reports to the national electronic injury surveillance system. Ann Otol Rhinol Laryngol 1992; 101: 739-42.

17 Consumer Safety Unit. Home accident surveillance system. Data. London: Department of Trade and Industry, 1991.

18 World Health Organisation. Manifesto for safe communities.
Stockholm: World Conference on Accident and Injury Prevention, 1989.

19 Shepherd RT. Accidental self-strangulation in a young child - a case report and review. Med Sci Law 1990; 30 119-23.

20 Yee WH. Accidental strangulation by window-blind cords [letter]. Can Med Assoc F 1990; 142: 436.

21 Kemp AM, Sibert JR. Epilepsy in children and the risks of drowning. Arch Dis Child 1993; 68: 684-5.

22 Templeman $C$. Two hundred and fifty eight cases of empleman C. Two hundred and fifty eight cases of suffocation of infants. Edinburgh Medical fournal 1892

eldman KW, Simms RJ. Strangulation in childhood: epidemiology and clinical course. Pediatrics 1980;65: 1079-85.

24 Cooke CT, Cadden GA, Hilton JMN. Hanging deaths in children. Am $\mathcal{F}$ Forensic Med Pathol 1989; 10: 98-104.

25 Office of Population Censuses and Surveys. 1. Mortality statistics. Cause. England and Wales. London: HMSO, 1972-1992.

26 Herman SP. Recovery from hanging in an adolescent male. Clin Pediatr (Phila) 1974; 13: 854-60.

27 Tertinger DA, Green BF, Lutzker JR. Home safety: development and validation of one component of an ecobehavioural treatment program for abused and neglected children. If Appl Behav Anal 1984; 17: 159-74.

\section{Look what I can do with my shoulder}

Some children are able to subluxate one or both shoulders at will and do so regularly to amuse or amaze their friends and colleagues. Whether this practice does any harm or whether surgical treatment to stop it is ever justified has not been known. In a Swiss orthopaedic clinic 26 children (13 boys and 13 girls) with this ability were seen over a period of 20 years and 25 of them were followed up for between six and 26 years (Harry Huber and Christian Gerber, Fournal of Bone and foint Surgery (British Volume) 1994; 76: 118-22). It had first been noticed at between 2 and 14 years of age. The instability affected only one shoulder in 12 of the 25 children and the direction of subluxation was most commonly posterior but some went anteriorly or inferiorly and 10 children could do it in more than one direction. In none was it the result of known trauma. The joints were all pain free at first but four children later developed pain on shoulder movement. Nobody in this series developed osteoarthritis of an affected shoulder. Eighteen children were simply advised to stop the voluntary subluxation and were not subjected to operation. They did well. The shoulder instability did not cause any disability and did not appear to influence or restrict their choice of occupation as adults. Seven eventually lost the ability to subluxate their shoulder(s). Seven children were operated on and they did less well. Only three of them (five of 10 operated shoulders) were considered to have had a satisfactory result; two shoulders were painful, one stiff, and two unstable after operation.

The authors conclude, reasonably, that these children should not be submitted to operation.

ARCHIVIST 